\title{
Morphine Responsiveness and Seizure Proneness
}

\author{
Alfred Mansour and Elliot S. VAlenstein ${ }^{1}$ \\ Department of Psychology and Neuroscience Laboratory, \\ University of Michigan, Ann Arbor, Michigan 48109
}

Received December 27, 1983; revision received March 19, 1984

\begin{abstract}
Previous research demonstrated that following amygdala kindling, animals showed a heightened sensitivity to morphine's convulsive effects and an exaggerated Straub tail response. These effects were evident to 3 months after their last convulsion and could be blocked by naloxone pretreatment. The present paper extends these findings by demonstrating that animals given metrazol or electroshock (ECS) convulsions also showed an enhanced morphine response that was blocked by naltrexone. Both metrazoland ECS-treated animals convulsed in response to doses of morphine that produced little or no effect in control animals. In addition, it was shown that brain damage induced by electrode implantation or neocortex penetration by skull screws also increased an animal's sensitivity to morphine even in the absence of prior convulsions. This effect, however, could not be blocked by naltrexone. Finally, as opiate receptors vary with the diurnal rhythm, we determined that following amygdala kindling, animals are more sensitive to morphine's convulsive action during their dark phase when receptor number and sensitivity are highest. The results indicated that seizure proneness, whether induced by a history of prior convulsions or brain damage, increased sensitivity to morphine. This effect may be due to a change in opiate receptors only when prior convulsions have occurred.
\end{abstract}

\section{INTRODUCTION}

Previous research in our laboratory demonstrated that kindling produces long-lasting changes in responsiveness to opiates $(11,12)$. Typically only very high, and usually lethal doses, of morphine are able to induce convulsions in normal mice. After undergoing amygdala kindling, mice show a high incidence of clonic convulsions and an exaggerated Straub tail response to relatively low doses of morphine. Changes in morphine responsiveness can

Abbreviations: ECS—electroconvulsive shock, GC-generalized convulsion.

${ }^{1}$ The authors acknowledge the support of National Institutes of Health grant 5 F31 DA0520603, National Science Foundation grant BNS-8025468, and Dr. James Woods for the contribution of naltrexone. 
be detected to 3 months after an animal's last stimulation-induced convulsion. Moreover, the morphine-induced convulsions observed in kindled animals do not appear to be a nonspecific action of the drug, as they can be blocked by small doses of naloxone.

In our earlier study, we also observed that animals kindled in the neocortex showed the same changes in morphine responsiveness as seen after amygdala kindling (11). It seemed, therefore, that the change was not specific to kindling of a particular brain structure, and might occur after a regimen of convulsions induced by means that are not known to produce an epileptogenic brain focus. To test this possibility, we determined whether or not repeated metrazol or electroshock (ECS) convulsions produce the changes observed to follow kindling with brain electrodes. As our results demonstrated that morphine responsiveness was also changed after metrazol and ECS convulsions, we determined if these effects could be blocked by naltrexone pretreatment.

Although the results obtained after metrazol and ECS convulsions extended our earlier observations, the role of kindling in producing the enhanced responsiveness to morphine became less certain. There are a number of reports indicating that kindling occurs with metrazol, as initially subconvulsive doses after repeated injections will produce convulsions (4). It is less clear, however, whether or not repeated ECS produces a kindling effect. Although it has been claimed in the clinical literature that kindling does not occur with repeated ECS (20), more recent reports indicate that under certain conditions "ECS kindling" does occur in rats (15) and in mice (16). These discrepancies may be due to species differences, or to differences in the interval between electroshocks typically used clinically and in animal research.

In view of the unresolved controversy over the question of "ECS kindling," it is not clear whether the increased sensitivity to morphine is reflecting an enhanced seizure-proneness or a relatively long-lasting change produced by generalized convulsions. This question was pursued by testing the sensitivity to morphine of animals that never had a convulsion, but were suspected of being more seizure-prone because they had experienced brain damage (1). We tested animals after either electrode implantation, or penetration of the skull and cortex by the screws normally used to attach electrodes to the head. As the results revealed that brain damage without convulsions increased sensitivity to morphine, we tested the capacity of naltrexone to block this effect.

Last, even though we demonstrated that the change that follows amygdala kindling, metrazol, or ECS could be blocked by naloxone or naltrexone, it was not obvious whether the change in responsiveness to morphine was due to modification of opiate receptors or to some other brain changes that lowered convulsion thresholds and could be accessed through opiate receptor mechanisms. Although this is a difficult question to answer in a definitive 
way, as a first step, we determined whether or not the probability of inducing convulsions in kindled animals was correlated with reported changes in opiate receptors. As studies have indicated that rats show a greater sensitivity to morphine's analgesic and locomotor effects $(2,5)$ as well as an increased receptor number (13) during the dark phase of their day-night cycle, we examined the effects of diurnal rhythm on morphine-induced convulsions in kindled mice.

\section{METHODS}

\section{General Methods}

All animals used in the following experiments were adult C57BL/6J mice either bought from Jackson Laboratories, Bar Harbor, Maine, or bred in our laboratory from Jackson stock. The animals were maintained on a 12-h light:12-h dark cycle with food and water available ad libitum. The injections of morphine sulfate, metrazol, naltrexone, or saline were intraperitoneal. All drug data points were based on a minimum of six animals with the one exception noted below. With the exception of experiment IV, the morphine tests were administered 1 to $5 \mathrm{~h}$ after the beginning of the dark phase.

The range of doses was based on the results from pilot experiments. When a range was established, appropriate doses were selected for the studies reported here. The animals were randomly assigned to a drug condition and tested only once. The percentage of animals showing a generalized convulsion, including clonic limb movements and falling, was recorded for each drug condition in each of the experiments.

Experiment I: Comparison of the Effect of Seizures Induced by Amygdala Kindling, Metrazol, or Electroconvulsive Shock on Morphine Sensitivity

Surgery, Amygdala Kindling, and Morphine Dose-Response Curve. A total of 56 mice was implanted with bipolar electrodes in the amygdala. With the skull level, the stereotaxic coordinates were $1.5 \mathrm{~mm}$ posterior to bregma, 3.5 $\mathrm{mm}$ lateral, and $4.5 \mathrm{~mm}$ below the dorsal surface of the skull. Using those coordinates, electrodes typically were placed in the center of the amygdala complex. The electrodes consisted of two twisted, Teflon-coated, stainlesssteel wires $(0.1524 \mathrm{~mm}$ diameter) soldered to microminiature pins (Winchester Co. 8456).

Following recovery from surgery the animals were assigned to one of two groups; one group received brain stimulation $(N=31)$ and the other group served as handled, implanted controls $(N=25)$. The experimental animals were stimulated once daily with a 1-s duration, $50 \mu \mathrm{A}, 60 \mathrm{~Hz}$ sine wave 
current until they showed seven consecutive generalized convulsions (stages 5 through 7). The kindled convulsions were rated according to the following scale (14): 1 = mouth movements, 2 = head nodding, 3 = clonus, $4=$ clonus plus rearing, $5=$ generalized convulsion $(\mathrm{GC})$ plus rearing and falling, 6 $=\mathrm{GC}$ plus repeated rearing and falling, $7=\mathrm{GC}$ plus repeated rearing and falling followed by running.

Three days after their last convulsion, the kindled animals were given one of four morphine doses $(3,10,17$, or $25 \mathrm{mg} / \mathrm{kg}$, i.p. ) and observed $90 \mathrm{~min}$ for the appearance of morphine-induced convulsions. The control animals were handled identically to the kindled animals and tested with either 10 , 25,60 , or $100 \mathrm{mg} / \mathrm{kg}$ morphine.

Metrazol Procedure and Dose-Response Curve. Unpublished work in our laboratory had shown that when a constant dose of metrazol is administered daily, C57 mice have progressively more severe convulsions and generally die after their third or fourth convulsion. We therefore used a dose titration procedure which allowed us to give animals seven generalized metrazol convulsions. All the experimental mice $(N=18)$ received an initial screening dose of metrazol $(50 \mathrm{mg} / \mathrm{kg}$, i.p.). Those animals that convulsed were given $45 \mathrm{mg} / \mathrm{kg}$ metrazol the following day. If they continued to show convulsions the dose was reduced by $5 \mathrm{mg} / \mathrm{kg}$ daily until they had seven convulsions. If a convulsion was not elicited on 2 consecutive days the dose was increased by $5 \mathrm{mg} / \mathrm{kg}$ every 2 days until a convulsive dose was reached. On subsequent days, the dose reduction procedure described above was repeated. Those animals not showing a convulsion to the screening dose of metrazol for 2 consecutive days received progressively larger doses on subsequent days until a convulsion was elicited. The dose of metrazol was then titrated as described. Using this procedure, animals attained the criterion of seven generalized convulsions within 13 to 27 days of metrazol treatment. Control animals ( $N$ $=21$ ) were handled identically to the metrazol-treated animals except they were injected daily with saline. Three days after the last metrazol convulsion, the experimental animals were tested for morphine-induced convulsions with either 25,60 , or $100 \mathrm{mg} / \mathrm{kg}$ morphine. Control animals werc similarly tested with either 100,300 , or $600 \mathrm{mg} / \mathrm{kg}$ morphine.

Electroconvulsive Shock Procedure and Morphine Dose-Response Curve. Mice $(N=20)$ received seven corneal electroshock convulsions and were tested 3 days later for morphine-induced convulsions. The procedure consisted of delivering electricity $(6.5 \mathrm{~mA}, 0.5 \mathrm{~s})$ via two saline-soaked gauze pads attached to wooden dowels and placed against the cornea of each eye. Control animals $(N=21)$ were handled identically except that they were not shocked. The experimental animals were tested with either 25,60 , or $100 \mathrm{mg} / \mathrm{kg}$ morphine, and the controls were injected with either 100,300 , or 600 $\mathrm{mg} / \mathrm{kg}$ morphine. 


\section{Experiment II. Naltrexone Blockade of Morphine-Induced Convulsions in Metrazol-treated, Electroconvulsed, or Chronically Implanted and Naive Animals}

Mice were given seven metrazol convulsions, seven ECS convulsions, or amygdala electrode implantation (without stimulation) as described in experiment I. Three days after their last convulsion or 28 days after electrode implantation, the animals were pretreated with various doses of naltrexone $(0.0,0.1,1.0,3.0,10.0$, or $30.0 \mathrm{mg} / \mathrm{kg}) 5 \mathrm{~min}$ prior to receiving $100 \mathrm{mg} / \mathrm{kg}$ morphine. We used this dose of morphine because it induced convulsions in approximately $70 \%$ of the ECS- and metrazol-treated animals and in $86 \%$ of implanted animals (experiment $\mathrm{I}$ ).

Naive mice $(N=14)$ were pretreated with either $60 \mathrm{mg} / \mathrm{kg}$ naltrexone or saline $5 \mathrm{~min}$ prior to $600 \mathrm{mg} / \mathrm{kg}$ morphine to test whether or not the convulsions observed in naive animals after very large doses of morphine are mediated by opiate receptors. The dose of $60 \mathrm{mg} / \mathrm{kg}$ naltrexone alone never produced convulsions in C57 mice (personal observation).

\section{Experiment III. Brain Damage and Morphine Sensitivity}

Brain damage was produced by screwing stainless-steel skull screws $(0 / 80)$ into the skull over the parietal, frontal, and occipital regions of mice $(N$ $=25$ ). The three screws protruded through the skull and penetrated approximately $0.85 \mathrm{~mm}$ into the underlying cortex. All screws were immediately removed after insertion. Control mice $(N=21)$ had a scalp incision made under the same anesthetia (phenobarbital, $80 \mathrm{mg} / \mathrm{kg}$ ) and were otherwise handled similarly to the experimental animals. The experimental and control mice were given either 100,300 , or $450 \mathrm{mg} / \mathrm{kg}$ morphine and tested 28 days postsurgery for morphine-induced convulsions. The selection of the 28-day interval was based on the average interval between surgery and morphine testing of the amygdala kindled animals.

\section{Experiment IV. Effects of Day-Night Cycle on Morphine-Induced Convulsions in Kindled Mice}

Mice $(N=19)$ were maintained on a 12 -h on:12-h off light-dark cycle with the lights going on at $0500 \mathrm{~h}$. All animals were implanted with amygdala electrodes as described in experiment I and were stimulated once daily between 0900 and $1200 \mathrm{~h}$. Three days after reaching the criterion of seven consecutive generalized convulsions, the animals were randomly divided into three groups. Two groups were injected with either $30 \mathrm{mg} / \mathrm{kg}(N=7)$ or $60 \mathrm{mg} / \mathrm{kg}(N=6)$ morphine between 0800 and $1100 \mathrm{~h}$ (light phase) and the third group $(N=6)$ was injected with $30 \mathrm{mg} / \mathrm{kg}$ between 1800 and $2000 \mathrm{~h}$ (dark phase). 
The animals were observed for morphine-induced convulsions during a 90 min test period.

\section{RESULTS}

Amygdala kindled, ECS, or metrazol convulsions produced a change in morphine responsiveness that was evident when animals were tested 3 days after their last convulsion (Fig. 1). Morphine convulsions were induced in a dose-dependent manner in kindled mice, with a maximal effect at 25 $\mathrm{mg} / \mathrm{kg}$ ( $89 \%$ of mice convulsed). In contrast, none of the implanted control mice showed a convulsion after this dose of morphine. In fact, it took four times this dose of morphine to produce a comparable effect $(86 \%$ of mice convulsed) in the implanted control animals.

Metrazol and ECS convulsions also changed an animal's responsiveness

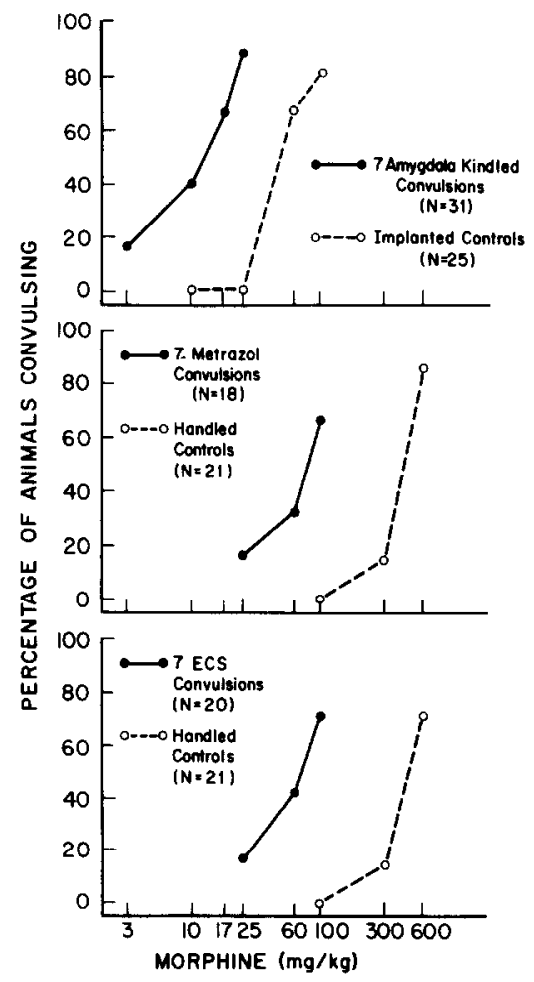

FIG. 1. Percentage of animals convulsing in response to different doses of morphine administered 3 days after seven amygdala-kindled, metrazol or electroconvulsive shock (ECS) convulsions. All control animals were handled equivalently and amygdala-kindled controls had implanted electrodes. All data points are based on six or more animals; the total number of animals is in parentheses. 
to morphine. Sixty-six percent of the animals previously treated with metrazol and $71 \%$ of the animals given ECS convulsed after a dose of $100 \mathrm{mg} / \mathrm{kg}$ morphine. In contrast, this dose of morphine never produced a convulsion in the unimplanted saline-injected or handled controls. Unimplanted control mice required doses of $300 \mathrm{mg} / \mathrm{kg}$ or greater before showing convulsions to morphine. The morphine-induced convulsions observed in the unimplanted control mice were usually lethal (12 of 13 animals) whereas those seen in ECS- and metrazol-treated animals never resulted in death. Similarly, doses of morphine necessary to induce convulsions in kindled $(25 \mathrm{mg} / \mathrm{kg})$ and in implanted control mice $(100 \mathrm{mg} / \mathrm{kg})$ never resulted in the animal's death.

Electrode implantation produced an increased sensitivity to morphine as is seen by comparing the response of implanted mice to either the unimplanted handled or saline-injected controls. Eighty-six percent of the implanted controls convulsed to a $100 \mathrm{mg} / \mathrm{kg}$ dose of morphine, whereas none of the handled or saline-injected controls convulsed at this dose (Fig. 1). Further, even the brain damage produced by the insertion and removal of skull screws altered the sensitivity of animals to morphine (Fig. 2). A greater percentage of brain damaged animals convulsed compared with their controls at each dose of morphine tested, with the largest difference occurring at $300 \mathrm{mg} / \mathrm{kg}$. Even at the $450 \mathrm{mg} / \mathrm{kg}$ dose, where the percentage of animals convulsing was similar, the brain damaged animals showed more severe convulsions, resulting in death in six of the seven animals tested. In contrast, only two of the five control mice that convulsed at this dose died.

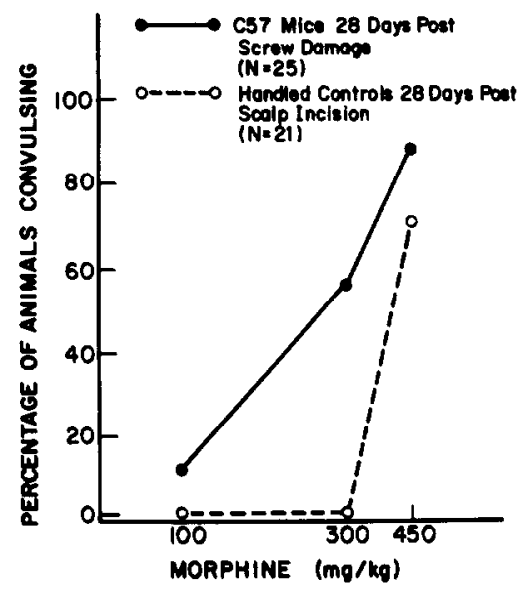

FiG. 2. Percentage of animals convulsing in response to different doses of morphine administered 28 days after insertion and removal of skull screws (see text for details). Controls were anesthetized and the scalp incised, and then tested with morphine 28 days later. All data points are based on six or more animals. Numbers in ( ) $=$ total numbers used. 
The morphine-induced convulsions observed in the ECS and metrazoltreated animals were blocked by naltrexone pretreatment (Fig. 3). A dose of 3.0 or $10.0 \mathrm{mg} / \mathrm{kg}$ naltrexone blocked the convulsive effects of $100 \mathrm{mg} / \mathrm{kg}$ morphine in the ECS- and metrazol-treated animals, respectively. In contrast, doses of $1.0,10.0$, or $30.0 \mathrm{mg} / \mathrm{kg}$ naltrexone failed to block the convulsions induced by morphine in animals with amygdala electrodes that were not kindled. Doses of 10 and $30 \mathrm{mg} / \mathrm{kg}$ naltrexone did, however, block the stereotyped running and Straub tail response that is normally seen with this dose of morphine. Similar results were observed in naive mice, in which naltrexone $(60 \mathrm{mg} / \mathrm{kg})$ was able to block the stereotyped running and Straub tail response but failed to block the convulsions observed with the 600 $\mathrm{mg} / \mathrm{kg}$ dose.

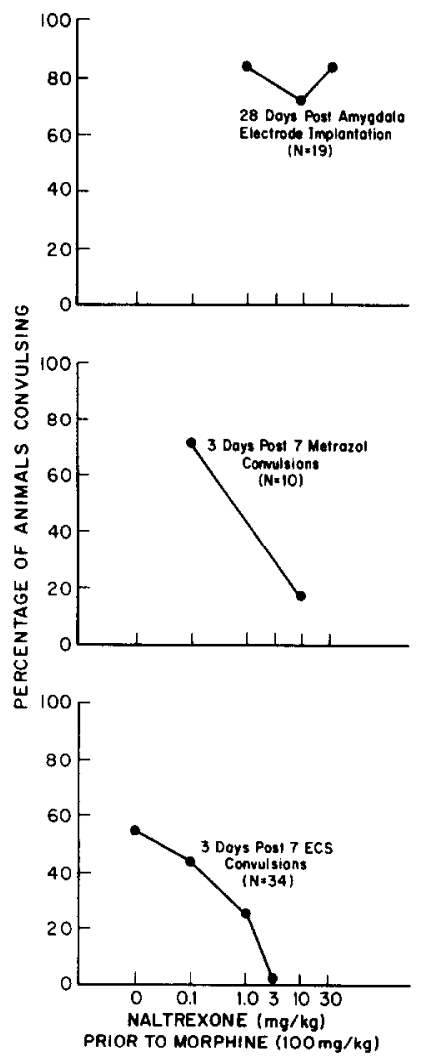

FlG. 3. Percentage of animals convulsing in response to $100 \mathrm{mg} / \mathrm{kg}$ morphine administered 5 min after different doses of naltrexone. Metrazol-treated and ECS groups were tested 3 days after their last convulsion. Animals with amygdala electrodes were handled daily and tested 28 days after surgery. All data points are based on six or more animals except for the metrazol group pretreated with $0.1 \mathrm{mg} / \mathrm{kg}$ naltrexone $(N=4)$. Numbers in $(\quad)=$ total numbers used. 
Figure 4 shows that the sensitivity of kindled mice to morphine-induced convulsions varied with the day-night cycle. Whereas $83 \%$ of the mice tested with $30 \mathrm{mg} / \mathrm{kg}$ morphine during the dark phase convulsed, only $29 \%$ of the mice tested in the light phase with the same dose of morphine convulsed (chi square $=3.9, P<0.05$ ). The effects seen with the $30 \mathrm{mg} / \mathrm{kg}$ dose in the dark phase were consistent with the dose-response relationship found in experiment 1 . The finding that $83 \%$ of the animals convulsed with a dose of $60 \mathrm{mg} / \mathrm{kg}$ morphine when tested during the light phase argues for a twofold change in sensitivity with the day-night cycle.

\section{DISCUSSION}

These results indicate that repeated ECS, metrazol, or kindled convulsions produce long-lasting changes in morphine responsiveness. The animals in each of these treatment groups showed a changed morphine responsiveness and convulsed at doses that produced no response in control animals. In an earlier publication (11) we reported that the induced morphine convulsions observed in kindled animals could be blocked by naloxone. The present study has shown that naltrexone pretreatment blocks the morphine-induced convulsions observed in metrazol- and ECS-treated animals.

Our results also show that electrode implantation or damage induced by insertion and removal of skull screws can increase an animal's sensitivity to morphine even without any prior convulsions. The morphine-induced convulsions observed in electrode-implanted animals are not, however, blocked

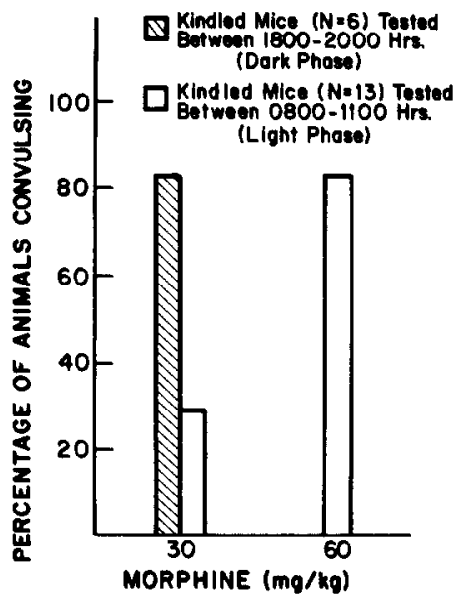

FIG. 4. Percentage of amygdala-kindled animals convulsing after 30 or $60 \mathrm{mg} / \mathrm{kg}$ morphine administered during the dark or light phase of their diurnal cycle. All data points are based on six or more animals. Numbers in ( ) $=$ total numbers used. 
by naltrexone pretreatment. This suggests that the change in morphine sensitivity observed to follow brain damage, in contrast to that seen after repeated convulsions, may not be due to changes in opiate receptors. Naltrexone was similarly unable to block the convulsions observed in naive animals produced by lethal doses of morphine. This is consistent with the findings of others who have been unable to block morphine's convulsive effects (7). These results may be explained by assuming that large doses of systemic morphine induce both opiate receptor-dependent and nonspecific effects. Naltrexone, while antagonizing the opiate receptor effects of morphine, does not antagonize the nonopiate convulsant effects observed in the naive and electrode-implanted animals.

The changes we observed in morphine responsiveness that follow electrode implantation or screw penetration of the neocortex may be the result of changes in GABA systems. Morphine has been reported (21) to inhibit GABA systems and such an effect might trigger convulsions, particularly in seizureprone animals. If this were the case, naltrexone would not be expected to block these morphine-induced convulsions. Consistent with this speculation is the report that opiate alkaloids and peptides antagonized GABA responses and this effect was not reversible by naloxone (21).

There are a number of different mechanisms that might explain the change in morphine responsiveness that follows repeated convulsions. It is unlikely that the changes in morphine responsiveness are due only to damage of the blood-brain barrier, as animals that have undergone electrode implantation, where the blood-brain barrier is certainly damaged, should have also shown a naltrexone-reversible change in morphine responsiveness. Yet, as is seen from our results, naltrexone failed to block the morphine-induced convulsions observed in implanted animals. A more probable explanation is that kindling, ECS, and metrazol produce a change in morphine responsiveness by increasing either opiate receptor number or affinity. The literature provides some support for such an explanation, as repeated ECS was reported to produce an increase in opiate receptor number in rats (9). It was also reported that ECS (10) and amygdala kindling (19) elevate enkephalin, and this finding may also explain the present results.

It is difficult to say at present which of the opiate receptor subpopulations might be changed by repeated convulsions. The doses of morphine used in our preparations are probably sufficiently large to stimulate more than just mu opiate receptors. Moreover, we recently found that kindled mice are more sensitive to ethylketazocine, a kappa receptor agonist, and these effects can be blocked by naloxone pretreatment (12). This raises the possibility that kindling or repeated convulsions induce changes in both mu and kappa receptors. Other investigators have implicated delta receptors in seizure mechanisms. For example, Frenk et al. (8) found that intraventricular in- 
jections of the delta receptor agonists, met- and leu-enkephalin, induce seizures at smaller doses than morphine. Similarly, Holaday et al. (9) reported that repeated ECS produced an increase in delta receptor number without changing receptor affinity. Based on our work and that of others (17), it seems likely that more than one and possibly all the opiate receptors participate in the mediation of seizures.

The change in morphine sensitivity with the day-night cycle is consistent with the notion that kindling produces changes in opiate receptors. Kindled mice were more sensitive to morphine-induced convulsions during the dark phase, a time when opiate receptor numbers peak (13). Nonetheless, any suggestion of a causal relationship should be considered as very tentative at this time because of the many other processes that vary with the diurnal cycle.

Our result demonstrating an altered responsiveness to morphine that follows a history of convulsions or brain damage raises the possibility of devising a test of seizure-proneness. We are aware of the many problems in such an approach. Although morphine is clearly a convulsant in our animals, its actions are species-specific. For instance, morphine has been shown to have both pro- and anticonvulsant action in the rat and its effects may vary with the route of administration [see (6) for review]. Urca and Frenk (18) found that although morphine increased the latency of onset of metrazol convulsions, it also increased the number of convulsions observed. Similarly, although a large dose of morphine can reduce the behavioral aspects of kindled convulsions, it also increases the duration of the electrographic seizures (3). Although these opposing actions of morphine complicate the problem, it is certainly conceivable that a model could be developed which emphasizes the change in responsiveness of seizure-prone animals to this drug. For obvious reasons, such a model would have to use a more benign end-point to assess responsiveness to morphinc than the induction of convulsions.

\section{REFERENCES}

1. ADLER, M. W. 1965. Increased sensitivity to pentylenetetrazol and flurothyl following cortical ablations in rats. J. Pharmacol. Exp. Ther. 148: 131-135.

2. AYHAN, I. H. 1974. Daily susceptibility variations to morphine-induced hyperactivity of rats. Commun. Pharm. Pharmacol. 26: 76-78.

3. Caldecott-Hazard, S., Y. Shavit, R. F. Ackermann, J. Engel, JR., R. C. A. FredERICKSON, AND J. C. LIEBESKIND. 1982. Behavioral and electrographic effects of opioids on kindled seizures in rats. Brain Res. 251: 327-333.

4. FABISIAK, J. P., AND W. S. SCHWARK. 1982. Aspects of the pentylenetetrazol kindling model of epileptogenesis in the rat. Exp. Neurol. 78: 7-14.

5. Frederickson, R. C. A., V. BURGIS, AND J. D. EdwARdS. 1977. Hyperalgesia induced by naloxone follows diurnal rhythm in responsivity to painful stimuli. Science 198: 756758. 
6. FRENK, H. 1983. Pro- and anticonvulsant actions of morphine and the endogenous opioids: involvement and interactions of multiple opiate and non-opiate systems. Brain Res. Rev. 6: $197-210$.

7. Frenk, H., A. Liban, R. Balamuth, and G. URCa. 1982. Opiate and non-opiate aspects of morphine induced seizures. Brain Res. 253: 253-261.

8. Frenk, H., G. URCA, AND J. C. LIEBESKIND. 1978. Epileptic properties of leucine- and methionine-enkephalin: comparison with morphine and reversibility by naloxone. Brain Res. 147: 327-337.

9. Holaday, J. W., R. J. Hitzemann, J. Curell, F. C. Tortella, and G. L. Belenky. 1982. Repeated electroconvulsivc shock or chronic morphine treatment increases the number of ${ }^{3} \mathrm{H}-\mathrm{D}-\mathrm{ALA}^{2}$, D-Leu ${ }^{5}$-enkephalin binding sites in rat brain membranes. Life Sci. 31: 2359-2362.

10. HonG, J. S., P. L. WoOd, J. C. Gillin, H. Y. T. YaNG, AND E. CostA. 1980 . Changes of hippocampal met-enkephalin content after recurrent motor seizures. Nature (London) 285: 231-232.

11. Mansour, A., R. Doyle, R. KaTZ, and E. S. Valenstein. 1981. Long-lasting changes in morphine sensitivity following amygdaloid kindling in micc. Physiol. Behav. 27: 11171120.

12. Mansour, A., AND E. S. Valenstein. 1982. Pharmacological evidence for changes in mu and kappa opiate receptors following amygdaloid kindling. Soc. Neurosci. Abstr. 8: 225.

13. NABER, D., A. WIRZ-JuSTICE, AND M. S. KAFKA. 1981. Circadian rhythm in rat brain opiate receptor. Neurosci. Lett. 21: 45-50.

14. Pinel, J. P. J., AND L. I. Rovner. 1978. Experimental epileptogenesis: kindling-induced epilepsy in rats. Exp. Neurol. 58: 190-202.

15. RAMER, D., AND J. P. J. PINEL. 1976. Progressive intensification of motor seizures produced by periodic electroconvulsive shock. Exp. Neurol. 51: 421-433.

16. Sangdee, P., S. A. TURKanis, AND R. Karler. 1982. Kindling-like effect induced by repeated corneal electroshock in mice. Epilepsia 23: 471-479.

17. SNEAD, O. C., III, AND L. J. BEARDEN. 1982. The epileptogenic spectrum of opiate agonists. Neuropharmacology 21: 1137-1144.

18. URCA, G., AND H. FrENK. 1980. Pro- and anticonvulsant action of morphine in the rats. Pharmacol. Biochem. Behav. 13: 343-347.

19. Vindrola, O., R. BRIONES, M. Asai, AND A. FernandeZ-Guardiola. 1981. Brain content of leu- and met-enkephalin changes independently during the development of kindling in the rat. Neurosci. Lett. 26: 125-130.

20. WEINER, R. D. 1984. Does electroconvulsive therapy cause brain damage? Behav. Brain Sci. 7: 1-53.

21. WERZ, M. A., AND R. L. MACDONALD. 1982. Opiate alkaloids antagonize postsynaptic glycine and GABA responses: correlation with convulsant action. Brain Res. 236: 107119. 